\title{
Evaluation of temperature and electrolyte concentration dependent Oxygen solubility and diffusivity in phosphoric acid
}

\author{
Michael Fleige $^{\mathrm{a} *}$, Kaspar Holst-Olesen $^{\mathrm{a}}$, Gustav Karl Henrik Wiberg ${ }^{\mathrm{b}}$ and Matthias Arenz ${ }^{\mathrm{a}, \mathrm{c} *}$ \\ ${ }^{a}$ Department of Chemistry, University of Copenhagen, Universitetsparken 5, $2100 \emptyset$, Copenhagen,
} Denmark

${ }^{\mathrm{b}}$ Nordic Electrochemistry ApS, clo Department of Chemistry, Universitetsparken 5, 2100

Kфbenhavn Ø, Denmark

${ }^{\mathrm{c}}$ Department of Chemistry and Biochemistry, University of Bern, Freiestrasse 3, 3012, Bern, Switzerland

*Corresponding authors: m.fleige@chem.ku.dk; matthias.arenz@dcb.unibe.ch

\begin{abstract}
Reactant diffusion and solubility is of utmost important for providing sufficient reactant concentrations at a catalytic active surface. In high temperature proton exchange membrane fuel cells (HT-PEMFCs) the electrolyte consists of concentrated phosphoric acid embedded into a polybenzimidazole (PBI) membrane. Despite the elevated operation temperature of $150^{\circ} \mathrm{C}$, the observed oxygen reduction reaction (ORR) rates in HT-PEMFCs are significantly lower than in low temperature PEMFCs. Reduced reactant transport in combination with site blocking is often mentioned as possible inhibition factors. As a step towards studying the ORR under realistic conditions in half-cell setups, in the present study we investigate the oxygen solubility and diffusivity in diluted phosphoric acid electrolyte in a temperature range of 5 to $80{ }^{\circ} \mathrm{C}$. The presented
\end{abstract}


work demonstrates and discusses under which conditions reliable data for these constants can be obtained. In particular it is shown that the product of oxygen solubility and diffusivity, which determines the oxygen mass transport, first increases as function of temperature, but then decreases again above $60{ }^{\circ} \mathrm{C}$. It seems that the decrease in oxygen solubility at higher temperatures is correlated to an increase in the apparent ORR activation energy.

Keywords: Phosphoric acid, oxygen solubility; oxygen diffusion coefficient; HT-PEMFC; Hydrodynamic Chronocoulometry 


\section{Introduction}

Energy conversion and storage devices are key components for renewable energy supply. To align demand and supply, renewable energy can be stored in chemical bonds, e.g. by electrolysis of water to hydrogen and oxygen, and later reconverted to electricity using a fuel cell. For such a scheme to be meaningful high conversion efficiencies are mandatory; i.e. the activity of the applied electrocatalysts must be high. Phosphoric acid (PA) fuel cells were one of the first commercially applied fuel cells. The modern day phosphoric acid fuel cell - the high temperature proton exchange membrane fuel cell (HT-PEMFC) - uses instead of liquid acid a membrane consisting of a polybenzimidazole (PBI) polymer that is doped with concentrated PA; the latter being responsible for proton conductivity $[1,2]$. Due to the low vapor pressure of concentrated PA, HT-PEMFCs can be operated conveniently between $150-180{ }^{\circ} \mathrm{C}$ without risk of significant losses of PA due to evaporation. By comparison, the ion conductivity of membranes (typically Nafion) used in low temperature (LT) PEMFCs is based on hydronium ions and thus requires liquid water molecules. Consequently, operation temperatures of LT-PEMFCs are limited to below $100^{\circ} \mathrm{C}$. For the same reason, LT-PEMFCs require humidified fuel gas in order to prevent drying out of the membrane on the anode side. The higher operation temperature of HT-PEMFCs leads to a more efficient use of the produced waste heat. Another advantage of HT-PEMFCs is the reduced adsorption strength of strongly adsorbing catalyst poisons as for instance $\mathrm{CO}$ owing to elevated operation temperature. Thus, HT-PEMFCs can tolerate lower fuel purity, which makes them suitable even for operation with $\mathrm{H}_{2}$-rich syngas generated by reforming of for instance natural gas. Although the latter is not a scheme for renewable energy supply, such use might help the marked entry. Indeed, it has been demonstrated that Pt-based HT-PEMFC electrodes at $150{ }^{\circ} \mathrm{C}$ can tolerate a CO content of about $5000 \mathrm{ppm}$ without significant reduction of the relative catalyst activity [3]. In LT-PEMFC electrodes operated at $85{ }^{\circ} \mathrm{C}$ the relative activity was reduced about $30 \%$ by only $20 \mathrm{ppm} \mathrm{CO}$ [4]. 
Despite these principal benefits in terms of convenient operation, increased $\mathrm{CO}$ tolerance, and suitability for reformed hydrocarbon fuels, HT-PEMFCs require a significant higher mass loading of Pt-based catalysts than LT-PEMFCs in order to achieve a given power output. This is in contrast intuition, which expects lower catalyst loadings due to faster reaction kinetics at elevated temperatures. The principle reason for the poor performance of the electrocatalysts in HT-PEMFCs is not completely understood. In any electrocatalytic reaction, the reaction rate is determined by the number of free active catalyst sites and by the mass transport of reactants and products to and from these active sites. Many studies have shown that the PA is a key factor for the observed lower current densities in HT-PEMFCs, while especially the oxygen reduction reaction (ORR) taking place on the cathode is severely affected by the PA electrolyte. The inhibiting effect of the electrolyte on the ORR activity has been often explained by strong adsorption of PA ions on active catalyst sites [5-9]. We have recently demonstrated using cyclic voltammetry that adding even trace amounts of PA to electrolyte solutions that weakly interact with Pt-catalyst surfaces can lower the ORR catalytic activity by more than one order of magnitude [10]. In another study we have shown by performing potential hold experiments that the apparent ORR diffusion-limited current density decays on a time scale of minutes in PA electrolyte solutions, while in $\mathrm{HClO}_{4}$ - and $\mathrm{H}_{2} \mathrm{SO}_{4}$-based solutions it decreases much less under the same conditions [11]. From the results we concluded that additional effects of reaction inhibition could play a role, which might involve building up of a mass transport limiting barrier at the electrode-electrolyte interface. Aside from processes at the interface, the solubility and diffusivity of dissolved gaseous reactants in the bulk of highly concentrated PA are important parameters to characterize the reactant mass transport in fuel cell electrodes [12-15]. Mass transport of reactant gases in electrode layers of PAFC and PEMFC is generally considered by thin-film models suggesting a surface coverage of catalyst particles or agglomerates with electrolyte films that have bulk properties [9,14-17]. 
Therefore knowledge of both solubility or concentration (c) and diffusivity (D) of a gas for a given PA concentration and temperature is helpful for investigating the performance inhibition of HTPEMFCs. Gubbins and Walker used gas chromatography for solubility studies of $\mathrm{O}_{2}$ at room temperature over the whole PA concentration range; these studies were extended to concentrated PA at temperatures up to $180{ }^{\circ} \mathrm{C}[18,19]$. Their attempts to determine $\mathrm{D}$ in a glass diaphragm cell in concentrated PA above $80{ }^{\circ} \mathrm{C}$ where unsuccessful due to corrosion issues and the very slow diffusion of $\mathrm{O}_{2}$ in the concentrated acid. Gan and Chin studied c and D over the whole concentration range at $23{ }^{\circ} \mathrm{C}$ [20]. They used a rotating ring disc electrode (RRDE) to obtain D from the "transit time" of the diffusion of $\mathrm{O}_{2}$ from the disc to the ring, and determined c from the diffusion limited ORR current at the disc. In a number of studies estimates for both c and D are presented at conditions relevant for HT-PEMFC operation: Klinedinst et al. obtained c and D simultaneously from current transients of the ORR on shielded Pt wire electrodes from 100 to 150 ${ }^{\circ} \mathrm{C}$ [21]. Following the concept introduced by Winlove et al. [22], studies on Pt microelectrodes were presented by Scharifker et al. and Gang et al. at temperatures up to $150{ }^{\circ} \mathrm{C}$, and by Essalik et al. up to $100{ }^{\circ} \mathrm{C}$ [23-25]. Related to the introduction of the PA-doped PBI membrane, Liu et al. studied $\mathrm{O}_{2}$ mass transport in $\mathrm{PBI}-\mathrm{H}_{3} \mathrm{PO}_{4}$ blends interfaced with $\mathrm{Pt}$ band microelectrodes [26]. The variety of above mentioned studies in pure concentrated PA and PA-doped PBI provide valuable estimates for solubility and diffusivity of $\mathrm{O}_{2}$ at working conditions of HT-PEMFCs. However, the data contain a significant spread, making correct quantification of $\mathrm{O}_{2}$ mass transport in HTPEMFCs difficult [13]. Furthermore, many research efforts are directed to additive-modified PA electrolytes that may improve the ORR for instance via changes in solubility and diffusivity of $\mathrm{O}_{2}$ or via a reduced specific adsorption [23,27-29]. This draws ongoing interest in solubility and diffusivity data of PA-based electrolytes at elevated temperatures. Methods involving macroelectrodes such as RDE [30] or RRDE [20] have the potential for fast determination of c and 
$\mathrm{D}$, but they are impeded by the low solubility of $\mathrm{O}_{2}$ in concentrated PA. In this regard, working in pressurized systems is advantageous [31-34]. As a step towards studying the ORR at realistic conditions in pressurized half-cell setups, in the present study we therefore investigate the oxygen solubility and diffusivity in diluted phosphoric acid electrolyte in a temperature range of 5 to $80{ }^{\circ} \mathrm{C}$. The presented work demonstrates and discusses under which conditions reliable data for these constants can be obtained using rotating disk electrode (RDE). The data are a basis for more complex studies in concentrated PA under pressurized conditions.

\section{Experimental}

The measurements were performed with a RDE system, which consisted of a rotator EDI101 combined with speed control unit CTV101 (Radiometer Analytical, France). The system was interfaced to an ECi-200 potentiostat operated with the EC4U software package (Nordic Electrochemistry). In the software a calibration was implemented that provides an accuracy of the applied rotation rate of $\pm 1 \mathrm{rpm}$. As working electrode a homemade polycrystalline-Pt (poly-Pt) RDE tip with geometrical surface area of approx. $0.0314 \mathrm{~cm}^{2} \mathrm{Pt}$ was used. It was made from a Pt rod of $99.99 \%$ purity (MaTeck, Germany) with diameter of $2 \mathrm{~mm}$ and a height of $3 \mathrm{~mm}$. Several RDE tips were designed in order to test different material combinations. As main body of a tip we used a cylinder $11 \mathrm{~mm}$ in diameter made out of either PEEK or PTFE. Main bodies were made with a 3 $\mathrm{mm}$ deep round cavity in the center that served for the insertion of an assembly of Pt rod and a ring of either PTFE or PFA. The rings with inner diam. $=2 \mathrm{~mm}$ and outer diam. $=4 \mathrm{~mm}$ were cut from PTFE or PFA tubing (Bohlender, Germany). After insertion of the rod-ring-assembly, the RDE tips were polished using first $\mathrm{SiC}$ grinding paper of 15 and $5 \mu \mathrm{m}$ grain size and thereafter deagglomerated alpha alumina suspensions of 1 and $0.3 \mu \mathrm{m}$ grain size (Struers, Denmark) on a polishing felt (Struers) wetted with water. After polishing the tips were cleaned ultrasonically first in isopropanol and finally in ultra-pure water three times for at least 10 minutes. A gold plated 
spring contact (PTR Messtechnik, Germany) was used for providing electrical contact between Pt electrode and stainless steel RDE shaft.

Two different electrochemical cells were used. For measurements at a fixed temperature of $25{ }^{\circ} \mathrm{C}$, the electrochemical cell was based on a $100 \mathrm{ml}$ Pyrex glass laboratory flask with a custom made lid made of PTFE. In order to support the RDE, the lid has conically tapered joint. Furthermore, it has several holes for inserting counter electrode (CE), reference electrode (RE) and for gas supply. CE and RE were built of Pt wire $0.6 \mathrm{~mm}$ in diameter and Pt gauze of $20 \times 20 \mathrm{~mm}(99.9 \%$, wire diam. $=$ $0.06 \mathrm{~mm}, 1024$ mesh $\mathrm{cm}^{-2}$ ) purchased from MaTeck, Germany. The Pt mesh RE was placed in a glass capillary which was purged with a small quantity of $\mathrm{H}_{2}$ gas in order to obtain the potential of the reversible hydrogen electrode (RHE) as reference potential for the WE. Therefore all potentials are given with respect to the potential of RHE. The capillary had an opening of approx. $0.5 \mathrm{~mm}$ in diameter and resembled a Haber-Luggin capillary. However, in order to achieve an undisturbed flow pattern towards the WE, the opening of the capillary was placed in the bulk of the cell instead of bringing it as close as possible to the WE surface. The volume of electrolyte in the cell was 70 ml. In order to avoid altering the concentration of the PA solutions during the measurements, all gases used except $\mathrm{H}_{2}$ for the RHE were humidified before entering the cell. For this, the gases were guided through a gas bubbler containing a volume of approx. $50 \mathrm{ml}$ of electrolyte of the same concentration as used during measurements. The PA solutions were kept at $25{ }^{\circ} \mathrm{C}$ by placing the electrochemical cell and the bubbler in a thermostated water bath. The temperature of the bath was controlled using a hot plate (IKA RET control /t, Germany) equipped with a PT100 resistance thermometer (Greisinger TF101P, Germany).

The electrochemical cell used for temperature dependent measurements was a thermostated, doublewalled glass cell. The cell has several conically tapered ground glass joints that serve as supports for the RDE, a reflux condenser, a gas inlet made out of glass, a closed glass tube for 
contamination-free temperature measurement in the electrolyte, and for $\mathrm{CE}$ and $\mathrm{RE}$. The same $\mathrm{Pt}$ materials were used for construction of $\mathrm{CE}$ and $\mathrm{RE}$ as in the single-walled glass cell. The compartment for the RHE was a closed glass tube with a sealed in ceramic frit (Mettler) as liquid junction to the cell. The volume of electrolyte in the cell typically was $225 \mathrm{ml}$. In order to maintain the PA concentration, the gas outlet was via a reflux condenser that was connected to the tap water system. For temperature control, a thermostat (Lauda, Germany) was used. Since temperatures of cell and thermostat can deviate from each other, the temperature of the PA electrolyte was confirmed by the EC4DAQ software using a thermocouple Type $\mathrm{J}$ (RS Components) with a maximum deviation of $-0.4{ }^{\circ} \mathrm{C}$ to the probe used for viscosity measurements. The PA solutions were prepared from 85.6 wt $\% \mathrm{H}_{3} \mathrm{PO}_{4}\left(\right.$ Merck, Suprapur $\left.{ }^{\odot}\right)$ and ultra-pure water (MilliQ, $\rho=18.2$ $\mathrm{M} \Omega \mathrm{cm}$, Total organic carbon $\leq 5 \mathrm{ppb}$ ). Argon gas (purity $\geq 99.999 \%$ ), oxygen gas and hydrogen gas (purity $\geq 99.995 \%$ ) was purchased from Air Liquide, Denmark.

The kinematic viscosity of the electrolyte solutions was measured using a Canon-Ubbelohde viscometer (capillary constant $0.004 \mathrm{cSt} / \mathrm{s}$ ). All viscosity measurements were performed in a thermostated water bath of 31 volume, which was controlled by the same equipment as used in the room temperature electrochemical measurements. Generally, the temperature close to the capillary was found deviating $\pm 0.1^{\circ} \mathrm{C}$ around the set value. However, at $80{ }^{\circ} \mathrm{C}$ temperature gradients of up to $\pm 0.5^{\circ} \mathrm{C}$ were observed during single measurements.

\section{Results and Discussion}

We start the discussion of electrochemical measurements with the results for varying PA concentrations at $25{ }^{\circ} \mathrm{C}$. At the beginning of each measurement, at least 50 cyclic voltammograms in the potential window 0.05 to $1.5 \mathrm{~V}$ with a scan rate of $1.0 \mathrm{~V} \mathrm{~s}^{-1}$ were applied to oxidize possible adsorbed organic impurities. For the temperature dependent measurements the upper potential was 
limited to $1.4 \mathrm{~V}$ to exclude $\mathrm{O}_{2}$ evolution. Cyclovoltammograms (CVs) of the poly-Pt electrodes recorded in the different Argon-saturated electrolytes are given in Fig. 1.

\section{(*Fig. $\left.1^{*}\right)$}

The shape of the CVs is typical for poly-Pt samples in acidic electrolyte: From 0.05 to approx. 0.3 $\mathrm{V}$ the $\mathrm{H}_{\text {upd }}$ features are clearly resolved. In this region, atomic hydrogen is adsorbed in negative going scan direction, while it desorbs in positive going scan direction. It is seen that the $\mathrm{H}_{\text {upd }}$ features get less distinct in shape with increasing the PA concentration. Furthermore, the $\mathrm{H}_{\text {upd }}$ potential window slightly decreases, indicating competitive adsorption between hydrogen and phosphate. Towards more positive potentials between 0.4 and $0.8 \mathrm{~V}$ the currents are attributed to capacitive charging of the electrochemical double layer. Again a trend can be seen, i.e. increasing capacitive currents with increasing PA concentration. Further, around $0.8 \mathrm{~V}$ a peak emerges with increasing PA concentration. The reason for the emergence of the peak is not clear, but the peak is more clearly pronounced under forced convection (not shown). This points towards a possible PA species impurity, however, the used PA solution is the cleanest commercially available. Therefore, no effort was made to further purify the acid.

\section{(*Fig. 2*)}

In Fig. 2 polarization curves of the poly-Pt electrode in $\mathrm{O}_{2}$-saturated phosphoric acid obtained in RDE experiments are depicted. The onset of currents resulting from the ORR is observed for all PA concentrations at potentials $<1.0 \mathrm{~V}$. At high overpotential of the ORR, i.e. around $0.6 \mathrm{~V}$, the currents level out indicating that all $\mathrm{O}_{2}$ transported to the electrode surface is reduced. Further increasing the overpotential does not lead to increased currents, the electrode reaction is limited by diffusion of $\mathrm{O}_{2}$ to the surface. It is clearly visible that the diffusion limited currents decrease gradually from 0.05 to $5.0 \mathrm{~mol} \mathrm{dm} \mathrm{dm}^{-3}$ concentration. The RDE curve in $0.05 \mathrm{~mol} \mathrm{dm}{ }^{-3}$ electrolyte solution is less bended than curves in solutions of 0.5 or $1.0 \mathrm{~mol} \mathrm{dm} \mathrm{dm}^{-3}$ concentration. Indeed, a well- 
defined diffusion limited current plateau is only seen in the $0.05 \mathrm{~mol} \mathrm{dm}{ }^{-3}$ PA electrolyte solution; in the higher concentrated acids the curves exhibit a hysteresis between positive and negative going scan direction. The curves are more bended in positive going scan direction than in the negative ones. Further, it appears that in the negative going scans the bending decreases, when the concentration is raised further to 2.5 and $5.0 \mathrm{~mol} \mathrm{dm}^{-3}$. Diffusion limited currents go through a peak around $0.3 \mathrm{~V}$.

\section{$(*$ Fig $3 *)$}

In addition to the concentration dependence, we studied the temperature dependence of the CVs at fixed electrolyte concentration. In Fig. 3 a series of CVs recorded in $0.5 \mathrm{~mol} \mathrm{dm}{ }^{-3}$ phosphoric acid solution at temperatures from 5 to $80{ }^{\circ} \mathrm{C}$ is presented. The previously discussed typical features of poly-Pt are present over the whole temperature range. However, the $\mathrm{H}_{\text {upd }}$ peaks tend to be less resolved at increased temperature. The position of the first $\mathrm{H}_{\text {upd }}$ peak is similar at all temperatures, while the position of the second main $\mathrm{H}_{\text {upd }}$ peak is shifted towards lower potentials at increased temperatures. Similar to the previous observation, an additional peak emerges in the double layer region at increased temperature. Also here the feature becomes more visible under forced convection, see Fig. S1. In addition, in the potential region above $0.8 \mathrm{~V}$ a gradual increase of currents from the adsorption of oxygenated species is seen upon temperature increase. The increase of the adsorption currents is most pronounced increasing the temperature from 60 to $80{ }^{\circ} \mathrm{C}$.

\section{$(*$ Fig $4 *)$}

In Fig. 4 the corresponding RDE curves, i.e. polarization curves recorded in $\mathrm{O}_{2}$-saturated 0.5 mol $\mathrm{dm}^{-3}$ phosphoric acid in the temperature range from $5-80{ }^{\circ} \mathrm{C}$, are displayed. It is obvious that the shape of the curves and the diffusion limited current densities significantly vary temperature. In negative going direction (Fig. 4A) the polarization curve is strongly bended at $5{ }^{\circ} \mathrm{C}$. The bending 
decreases successively with increasing temperature. At 60 and $80{ }^{\circ} \mathrm{C}$ it completely diminishes, and a flat diffusion limited current plateau is observed at potentials $<0.6 \mathrm{~V}$. In positive going scan direction (Fig. 4B) the bending does not diminish upon temperature increase. In fact, the shape of the curves indicates that towards higher temperatures, in contrast to the observation in negative scan direction, a process is taking place that disturbs establishing a well-defined diffusion limited profile. For instance, at $80{ }^{\circ} \mathrm{C}$ the current density goes through a minimum at $0.53 \mathrm{~V}$. Focusing on the diffusion limited currents at $0.3 \mathrm{~V}$ in the more defined negative scans, the trend $\mathrm{j}\left(80^{\circ} \mathrm{C}\right)<\mathrm{j}\left(5^{\circ} \mathrm{C}\right)<$ $\mathrm{j}\left(25^{\circ} \mathrm{C}\right)<\mathrm{j}\left(60^{\circ} \mathrm{C}\right)$ is seen. The observed different shapes in positive and negative going scan direction indicate that the state of the electrochemical interface varies depending on the Pt-surface. Furthermore, the measured diffusion limited current density in PA electrolyte of higher concentration than $0.05 \mathrm{~mol} \mathrm{dm}^{-3}$ depends on the potential scan rate. The effect is illustrated in Fig. S2.

This raises the question, to which extent interactions between the Pt surface and PA species can affect current transients in the following hydrodynamic chronocoulometry (HC) experiments.

$\mathrm{HC}$ experiments are a method for simultaneous determination of the solubility and diffusivity of reactants and were applied for $\mathrm{O}_{2}$ in PA electrolyte solutions. The method was originally proposed by Morris [35] and developed further by Tsushima et al [30]. $\mathrm{HC}$ studies for $\mathrm{O}_{2}$ in various solutions such as aqueous $\mathrm{KOH}$, and room temperature ionic liquids have been published [36-39]. In these chronocoulometry experiments the electrode potential is stepped from a potential where no reaction of the reactant occurs to a potential where all reactant transported to the electrode surface is consumed (diffusion limited potential region). Based on the ORR studies discussed above, we chose for the latter a potential of $0.3 \mathrm{~V}$. At this potential for all tested conditions, oxygen is completely 
reduced to $\mathrm{H}_{2} \mathrm{O}$ and the ORR current is under diffusion control. At potentials $<0.3 \mathrm{~V}$ oxygen reduction to $\mathrm{H}_{2} \mathrm{O}_{2}$ might occur [40], which requires only two electrons, thus leading to deviations in the electrode current.

\section{(*Fig. $\left.5^{*}\right)$}

The potential step and electrode preconditioning profile used in this work for the individual HC experiments is displayed in Fig. 5. First, the electrode is pre-conditioned by reversing its potential three times between 0.05 and $1.4 \mathrm{~V}$ with a scan rate of $500 \mathrm{mV} \mathrm{s}^{-1}$. The preconditioning series is followed by another cyclovoltammogram with the same scan rate, where the upper potential is limited to a potential of $1.05 \mathrm{~V}$. Then, the electrode was allowed to rest for $5 \mathrm{~s}$ for equilibration at $1.05 \mathrm{~V}$ - in some measurements at $1.0 \mathrm{~V}$ - before the potential step to $0.3 \mathrm{~V}$. The electrode potential was held for $1 \mathrm{~s}$ at $0.3 \mathrm{~V}$ after the step. The RDE rotation rate was $600 \mathrm{rpm}$ in all $\mathrm{HC}$ measurements. In each measurement, at least 5 individual current transients in Argon- and $\mathrm{O}_{2}$-saturated solution were recorded, which were averaged during the data treatment. The average background (BG) transient in Ar-saturated solution was subtracted from the average of the ORR transients [41]. To facilitate reasonable subtraction of BG-transients, a good control over the uncompensated solution resistance was crucial [42]. This requires avoiding changes of applied compensation between measurements and stable cell geometry. The obtained average ORR transient was used for constructing a Q-t-plot to which a linear regression line is fitted over time intervals where the current has stabilized to the diffusion limited value. From the ratio of intercept and slope of the linear fit the Sc number can be determined, which characterizes the relationship of viscosity of the solution to the diffusivity of a dissolved species:

$S c=\frac{v}{D}$ 
Calculation of Sc requires solving eq. 23 given in ref. [30]. Once $\mathrm{D}_{\mathrm{O}_{2}}$ is determined, $\mathrm{c}_{2}$ can be obtained from the determined intercept and slope expressing the measured charge-time-relationship given in eq. 22 in ref. [30]

$Q=0.367 n F A c^{*} \delta+\left(\frac{n F A D c^{*}}{\delta}\right) t$

with $n$ the reaction electron number, Faraday's constant $F=96,485 \mathrm{C} \mathrm{mol}^{-1}, A\left(\mathrm{~cm}^{2}\right)$ the geometrical surface area of the disc electrode, $c^{*}\left(\mathrm{~mol} \mathrm{~cm}^{-3}\right)$ the bulk concentration of $\mathrm{O}_{2}, \delta(\mathrm{cm})$ the thickness of the hydrodynamic boundary layer extended by Newman $[30,43]$ and $t$ (s) the reaction time interval. According to Tsushima et al. the intercept term is the charge passed by consuming the reactant contained initially in the hydrodynamic boundary layer, and the slope term is equivalent with the Levich limiting current [30]. The chosen time interval for fitting the linear regression curves to Q-t-plots took into account that the stabilization time to obtain diffusion limited currents was different, depending on the viscosities of the solutions. Generally, the start of the time interval was chosen at minimized times after the step, since the stabilized diffusion limited currents had a noticeable decreasing trend. This observation is in line with the dependence of the diffusion limited currents on the scan rate given in Fig S2. Representative examples of raw data curves (Fig. S6 and Fig. S7) and relevant Charge-time-plots (Fig. S8 and Fig. S9) are given in the SI. The viscosity of the different PA solutions was determined using a capillary viscometer. The measured kinematic viscosities of the PA solutions are summarized in Table 1. 
Table 1: Kinematic viscosity of PA solutions and pure water at various temperatures $-\mathrm{n}$ is the amount of individual measurements for each combination of concentration and temperature, $v$ is the kinematic viscosity, and $\Delta v$ is the standard deviation of the individual viscosity measurements.

\begin{tabular}{|lllll|}
\hline$[\mathrm{PA}] / \mathrm{mol} \mathrm{dm}^{-3}$ & $\mathrm{~T} /{ }^{\circ} \mathrm{C}$ & $\mathrm{n}$ & $v / \mathrm{cm}^{2} \mathrm{~s}^{-1}$ & $\Delta v / \mathrm{cm}^{2} \mathrm{~s}^{-1}$ \\
\hline 0.05 & $25 \pm 0.1$ & 5 & 0.00915 & 0.00002 \\
0.5 & & 5 & 0.01002 & 0.00002 \\
1.0 & & 5 & 0.01105 & 0.00002 \\
2.5 & & 3 & 0.01487 & 0.00001 \\
5.0 & & 5 & 0.02572 & 0.00003 \\
0.5 & $5 \pm 0.1$ & 4 & 0.01694 & 0.00003 \\
& $15 \pm 0.1$ & 4 & 0.01276 & 0.00003 \\
& $40 \pm 0.1$ & 5 & 0.00739 & 0.00002 \\
& $60 \pm 0.1$ & 5 & 0.00529 & 0.00001 \\
0 & $80 \pm 0.5$ & 4 & 0.00408 & 0.00002 \\
& $5 \pm 0.1$ & 3 & 0.01537 & 0.00002 \\
& $25 \pm 0.1$ & 3 & 0.00909 & 0.000002 \\
& $80 \pm 0.5$ & 3 & 0.00373 & 0.00001 \\
\hline
\end{tabular}

In Table 2 the results of $\mathrm{HC}$ measurements at $25^{\circ} \mathrm{C}$ in the concentration range of 0.05 to $5.0 \mathrm{~mol} \mathrm{dm}^{-}$ 3 are summarized. The measured diffusion coefficient for $0.05 \mathrm{~mol} \mathrm{dm}{ }^{-3} \mathrm{PA}$ is similar to experimental literature values for pure water at $25^{\circ} \mathrm{C}$ given in Table 3 . As expected, a decreasing trend for diffusion coefficient and $\mathrm{O}_{2}$ concentration is measured, when the PA concentration increases. The deviation of the diffusion coefficient is around $10 \%$ for two individual measurements. However, for the $2.5 \mathrm{~mol} \mathrm{dm}^{-3}$ measurements the deviation is $60 \%$. For the same PA concentration also the maximum deviation of the measured concentration of $\mathrm{O}_{2}(12 \%)$ is seen. The ORR specific activity per geometrical surface area of poly-Pt electrode was extracted from a Tafel plot at $0.8 \mathrm{~V}$ included in the SI as Fig. S3. Towards increasing PA concentration, a pronounced reduction of the catalytic activity is seen, as expected from our previous results in more diluted PA [10]. Comparing the trends for the $\mathrm{O}_{2}$ diffusion coefficient and its solubility to the 
determined ORR activity, a clear correlation between them becomes apparent. To the best of our knowledge, this is the first time that such a clear correlation is shown for phosphoric acid.

Table 2: Diffusion coefficients \& concentration of $\mathrm{O}_{2}$, and kinetic current densities of poly-Pt at $\mathrm{E}$ vs. $\mathrm{RHE}=$ $0.8 \mathrm{~V}$ in PA solutions with concentrations ranging from 0.05 to $5.0 \mathrm{~mol} \mathrm{dm}^{-3}$ at $25 \pm 0.1^{\circ} \mathrm{C}$

\begin{tabular}{|ccccc|}
\hline $\begin{array}{c}{[\mathrm{PA}] / \mathrm{mol}} \\
\mathrm{dm}^{-3}\end{array}$ & $\begin{array}{c}\mathrm{t} \text { (lin. reg. }) \\
/ \mathrm{s}\end{array}$ & $\begin{array}{c}\mathrm{D} 2 \\
\mathrm{D}^{-5} \mathrm{~cm}^{2} \mathrm{~s}^{-1}\end{array}$ & $\begin{array}{c}\mathrm{c}_{\mathrm{O} 2} \\
/ 10^{-6} \mathrm{~mol} \mathrm{~cm}^{-3}\end{array}$ & $\begin{array}{c}\mathrm{j}_{\mathrm{k}}(\mathrm{geo}) \\
/ \mathrm{mA} \mathrm{cm}^{-2} \\
(\mathrm{E} \mathrm{vs.} \mathrm{RHE} \\
=0.8 \mathrm{~V})\end{array}$ \\
\hline 0.05 & $0.4-0.5$ & 2.18 & 1.17 & 1.33 \\
\hline 0.5 & $0.5-0.6$ & 1.60 & 1.22 & 1.07 \\
\hline 1.0 & $0.5-0.6$ & 1.75 & 1.23 & 1.03 \\
\hline 2.5 & $0.7-0.8$ & 1.83 & 1.08 & 0.79 \\
\hline 5.0 & $0.9-1.0$ & 1.01 & 1.06 & 0.4 \\
& & 1.62 & 0.95 & \\
\hline
\end{tabular}

(*Fig. 6*)

In order to test the $\mathrm{HC}$ method for determining the $\mathrm{O}_{2}$ diffusion coefficient and its solubility, we compare our data to previous work. In literature in general the product of the $\mathrm{O}_{2}$ diffusion coefficient and $\mathrm{O}_{2}$ concentration is plotted versus the electrolyte concentration. In Fig. 6, such a plot comparing our results to previous studies in phosphoric acid [20] and water [44] is shown. In the PA studies by Gan and Chin [20] a RRDE was used to measure the transit time of $\mathrm{O}_{2}$ from the disc to the ring to determine the diffusion coefficient. They obtained the concentration from the diffusion limited current on the disc using the Levich equation. Comparing our results to those by 
Gan and Chin, the trend for $\mathrm{C}_{2} \times \mathrm{D}_{2}$ is similar. However, in our work we obtain typically higher values for the same phosphoric concentration. A likely explanation is that Gan and Chin estimated the oxygen concentration from diffusion limited RDE curves at $50 \mathrm{mV} \mathrm{s}^{-1}$ [20]. It is clear from Fig. $\mathrm{S} 2$ that this can lead to an under-estimation of the concentration; the apparent diffusion limited currents depend on the scan rate in PA solutions of for instance $5 \mathrm{~mol} \mathrm{dm}^{-3}$ concentration.

Table 3: Diffusion coefficients \& concentration of $\mathrm{O}_{2}$, and kinetic current densities of poly-Pt at $\mathrm{E}$ vs. $\mathrm{RHE}=$ $0.8 \mathrm{~V}$ in $0.5 \mathrm{~mol} \mathrm{dm}^{-3} \mathrm{PA}$ in the temperature range from 5 to $80{ }^{\circ} \mathrm{C}$. As a comparison, literature values for diffusion coefficients and concentration of $\mathrm{O}_{2}$ in pure water are given.

\begin{tabular}{|c|c|c|c|c|c|c|c|c|}
\hline \multicolumn{5}{|c|}{ Phosphoric acid $\mathrm{c}=0.5 \mathrm{M}$} & \multicolumn{4}{|c|}{ Pure water } \\
\hline $\mathrm{T} /{ }^{\circ} \mathrm{C}$ & $\begin{array}{c}t \\
\text { (lin. reg.) } \\
/ \mathrm{s}\end{array}$ & $\begin{array}{l}\text { Do2 } \\
/ 10^{-5} \\
\mathrm{~cm}^{2} \mathrm{~s}^{-1}\end{array}$ & $\begin{array}{c}\mathrm{Co} 2 \\
/ 10^{-6} \mathrm{~mol} \\
\mathrm{~cm}^{-3}\end{array}$ & $\begin{array}{c}\mathrm{jk}_{\mathrm{k}}(\mathrm{geo}) / \\
\mathrm{mA} \mathrm{cm}{ }^{-2} \\
(\mathrm{E} \text { vs. RHE }= \\
0.8 \mathrm{~V})\end{array}$ & $\begin{array}{l}\text { po2 } \\
/ \mathrm{Pa}\end{array}$ & $\begin{array}{c}D_{02} \\
/ 10^{-5} \mathrm{~cm}^{2} \\
\mathrm{~s}^{-1} \\
{[44]}\end{array}$ & $\begin{array}{c}\mathrm{CO2} \\
/ 10^{-6} \mathrm{~mol} \mathrm{~cm}^{-3} \\
{[45]}\end{array}$ & $\begin{array}{c}\mathrm{CO2} \\
/ 10^{-6} \mathrm{~mol} \mathrm{~cm}^{-3} \\
{[46]}\end{array}$ \\
\hline 3.8 & & & & & & 1.09 & & 1.93 \\
\hline 5 & $\begin{array}{c}0.65- \\
0.75\end{array}$ & 1.07 & 1.79 & 0.55 & $\begin{array}{c}10045 \\
3\end{array}$ & & 1.91 & 1.88 \\
\hline 14.7 & & & & & & 1.55 & & 1.52 \\
\hline 15 & $0.6-0.7$ & 1.15 & 1.64 & 0.8 & 99620 & & 1.51 & 1.51 \\
\hline 25 & $0.5-0.6$ & & & 1.08 & 98157 & & 1.24 & 1.25 \\
\hline 25.3 & & & & & & 1.96 & & 1.24 \\
\hline 40 & $\begin{array}{c}0.55- \\
0.65\end{array}$ & 2.2 & 0.97 & 1.40 & 93944 & & 0.96 & 0.97 \\
\hline 40.2 & & & & & & 2.78 & & 0.96 \\
\hline 55 & & & & & 85573 & 3.64 & 0.77 & 0.75 \\
\hline 60 & $\begin{array}{l}0.35- \\
0.45\end{array}$ & 3.81 & 0.74 & 1.77 & 81392 & & & 0.69 \\
\hline 60.5 & & & & & & 4.03 & & 0.68 \\
\hline 80 & $\begin{array}{c}0.35- \\
0.45\end{array}$ & 5.58 & 0.44 & 1.95 & 53951 & & & 0.40 \\
\hline & & 6.03 & 0.40 & & & & & \\
\hline 80.1 & & & & & & 5.31 & & 0.40 \\
\hline
\end{tabular}


In Table 3 the results for $0.5 \mathrm{~mol} \mathrm{dm}{ }^{-3} \mathrm{PA}$ over the temperature range $5-80{ }^{\circ} \mathrm{C}$ are presented together with established literature values for water. The experimentally determined concentration of $\mathrm{O}_{2}$ in water is calculated based on Henry's coefficient from [45]. The partial pressure of $\mathrm{O}_{2}$ over water at the given temperatures was calculated as

$$
p_{\mathrm{O}_{2}}=101,325 \mathrm{~Pa}-p_{\mathrm{H}_{2} \mathrm{O}}^{S}
$$

with $\mathrm{p}^{\mathrm{s}} \mathrm{H}_{2} \mathrm{O}$ being the saturation vapor pressure of water [47]. The comparison shows that the results scatter fairly close around experimental data for diffusion coefficients and solubility of $\mathrm{O}_{2}$ in water. Due to the limited temperature range in [45], the table contains also values for the concentration of $\mathrm{O}_{2}$ in water calculated from a solubility model for $\mathrm{O}_{2}[46]$ to cover the temperature range above 55 ${ }^{\circ} \mathrm{C}$. Our measured concentration trend is in a fair agreement to these data.

\section{(*Fig. $7 *)$}

From the results presented in Table 3 the product $\mathrm{c}_{\mathrm{O}_{2}} \times \mathrm{D}_{\mathrm{O}_{2}}$ is calculated and plotted in Fig 7 . The temperature trend in $0.5 \mathrm{~mol} \mathrm{dm}{ }^{-3}$ PA compares fairly well to the analogous trend in pure water. In general, lower values of $\mathrm{c}_{2}$ and $\mathrm{D}_{\mathrm{O}_{2}}$ are expected in phosphoric acid-water-mixtures than in pure water, since the viscosity of phosphoric acid is higher, while the solubility of $\mathrm{O}_{2}$ in conc. $\mathrm{H}_{3} \mathrm{PO}_{4}$ is much lower than in water [20]. The decrease in $\mathrm{O}_{2}$ concentration when increasing the temperature can be expected to be less in $0.5 \mathrm{~mol} \mathrm{dm}^{-3}$ PA than in water due to lowered water vapor partial pressure. The highest value for $\mathrm{c}_{2} \times \mathrm{D}_{\mathrm{O}_{2}}$ at $60{ }^{\circ} \mathrm{C}$ agrees with the observation presented in Fig. 4 that at $60{ }^{\circ} \mathrm{C}$ the diffusion limited current densities are highest. Interestingly, $\mathrm{c}_{\mathrm{O}_{2}} \times \mathrm{D}_{\mathrm{O}_{2}}$ is higher at $80{ }^{\circ} \mathrm{C}$ than at $5{ }^{\circ} \mathrm{C}$, although the diffusion limited current densities given in Fig. 4 indicate a lower product at $80{ }^{\circ} \mathrm{C}$. However, as mentioned in the discussion of Fig. 2 and Fig. 4 the RDE curves have a bended shape for all solutions of $\mathrm{c}_{\mathrm{PA}}>0.05 \mathrm{~mol} \mathrm{dm}^{-3}$, and the bending is most pronounced at lower temperatures. These observations are indicators for interactions of Pt surface and PA species, 
which are likely to disturb the quantification of $\mathrm{c}_{2}$ and $\mathrm{D}_{\mathrm{O}_{2}}$ based on diffusion limited currents of the ORR on poly-Pt. Comparing the temperature dependence of the $\mathrm{O}_{2}$ diffusion coefficient and its solubility to the temperature dependence of the ORR activity, shown in Fig. S5 in the form of an Arrhenius plot, no clear correlation between apparent activation energy and $\mathrm{O}_{2}$ diffusion coefficient, but between apparent activation energy and $\mathrm{O}_{2}$ concentration is apparent.

\section{Conclusion}

The purpose of this study was to evaluate, whether hydrodynamic chronocoulometric measurements using RDE is a suitable methodology for electrochemical estimation of concentration and diffusivity of $\mathrm{O}_{2}$ in PA electrolytes. Both parameters were investigated in a concentration range of 0.05 to $5.0 \mathrm{~mol} \mathrm{dm}{ }^{-3}$ at a fixed temperature of $25{ }^{\circ} \mathrm{C}$ and over a temperature range from 5 to $80{ }^{\circ} \mathrm{C}$ at fixed concentration of $0.5 \mathrm{~mol} \mathrm{dm}{ }^{-3}$. Regarding the presented cyclovoltammetric results for the ORR, interactions of the Pt surface with the phosphoric acid electrolyte are likely to distort hydrodynamic chronocoulometric estimation of $\mathrm{O}_{2}$ concentration and diffusivity. Nevertheless, comparing to previous literature values for varying PA concentration at $23{ }^{\circ} \mathrm{C}$ [20], our data show the same trends. We believe that, although in some cases the scattering in our values is relative high, our $\mathrm{HC}$ data are in general more reliable, since using diffusion limited currents from polarization experiments at relative low potential scan rates seems to fail for accurate estimation of $\mathrm{O}_{2}$-saturation in PA solutions due phosphoric acid interaction with $\mathrm{Pt}$. The comparison of our measurements obtained in a temperature range from 5 to $80{ }^{\circ} \mathrm{C}$ to literature values of pure water shows that reasonable data for both $\mathrm{c}_{2}$ and $\mathrm{D}_{\mathrm{O}_{2}}$ can be estimated over a large temperature range. The maximum deviation of the measured $\mathrm{O}_{2}$ diffusivity compared to pure water was $35 \%$, and for the $\mathrm{O}_{2}$ concentration $10 \%$. Our results show that hydrodynamic chronocoulometry can be a useful tool also for measurements in PA electrolyte at operation temperatures of HT-PEMFCs, i.e. 
temperatures well above $100{ }^{\circ} \mathrm{C}$ and elevated pressure. Such measurements are currently under preparation. Correlating $\mathrm{O}_{2}$ diffusivity and $\mathrm{O}_{2}$ concentration to the ORR activity and its apparent activation energy, it is seen that increasing phosphoric acid electrolyte concentration leads to a decrease in all three $\left(\mathrm{O}_{2}\right.$ diffusivity, $\mathrm{O}_{2}$ concentration and ORR activity), whereas at higher temperatures $\mathrm{O}_{2}$ diffusivity increases, while $\mathrm{O}_{2}$ concentration is decreased concomitant to an increase in the apparent activation energy.

\section{Acknowledgements}

The research leading to these results has received funding from the European Union Seventh Framework Program (FP7/2007-2013) under Grant Agreement No. 309741 and the Danish Council for StrategicResearch (4M Centre). We acknowledge Prof. M. Inaba and Prof. H. Daimon from Doshisha University for their help in designing the electrochemical cells for the temperature dependent measurements.

\section{References}

[1] J.S. Wainright, J.-T. Wang, D. Weng, R.F. Savinell, M. Litt, Acid-Doped Polybenzimidazoles: A New Polymer Electrolyte, J. Electrochem. Soc. 142 (1995) L121123. doi:10.1149/1.2044337.

[2] D.I. MacDonald, J.R. Boyack, Density, electrical conductivity, and vapor pressure of concentrated phosphoric acid, J. Chem. Eng. Data. 14 (1969) 380-384. doi:10.1021/je60042a013.

[3] Q. Li, R. He, J.-A. Gao, J.O. Jensen, N.J. Bjerrum, The CO Poisoning Effect in PEMFCs Operational at Temperatures up to $200^{\circ} \mathrm{C}$, J. Electrochem. Soc. 150 (2003) A1599-A1605. doi:10.1149/1.1619984.

[4] S.J. Lee, S. Mukerjee, E.A. Ticianelli, J. McBreen, Electrocatalysis of CO tolerance in hydrogen oxidation reaction in PEM fuel cells, Electrochim. Acta. 44 (1999) 3283-3293. doi:10.1016/S0013-4686(99)00052-3.

[5] Q. He, B. Shyam, M. Nishijima, D. Ramaker, S. Mukerjee, Mitigating phosphate anion poisoning of cathodic Pt/C catalysts in phosphoric acid fuel cells, J. Phys. Chem. C. 117 (2013) 4877-4887. doi:10.1021/jp309282n.

[6] S. Mukerjee, S. Srinivasan, Enhanced electrocatalysis of oxygen reduction on platinum alloys in proton exchange membrane fuel cells, J. Electroanal. Chem. 357 (1993) 201-224. doi:10.1016/0022-0728(93)80380-Z. 
[7] R. Gisbert, G. García, M.T.M. Koper, Adsorption of phosphate species on poly-oriented Pt and $\mathrm{Pt}(111)$ electrodes over a wide range of pH, Electrochim. Acta. 55 (2010) 7961-7968. doi:10.1016/j.electacta.2010.04.009.

[8] D. Strmcnik, M. Escudero-Escribano, K. Kodama, V.R. Stamenkovic, A. Cuesta, N.M. Marković, Enhanced electrocatalysis of the oxygen reduction reaction based on patterning of platinum surfaces with cyanide., Nat. Chem. 2 (2010) 880-885. doi:10.1038/nchem.771.

[9] L. Qingfeng, X. Gang, H.A. Hjuler, R.W. Berg, N.J. Bjerrum, Limiting Current of Oxygen Reduction on Gas-Diffusion Electrodes for Phosphoric Acid Fuel Cells, J. Electrochem. Soc. 141 (1994) 3114-3119. doi:10.1149/1.2059286.

[10] K. Holst-Olesen, M. Nesselberger, M. Perchthaler, V. Hacker, M. Arenz, Activity inhibition and its mitigation in high temperature proton exchange membrane fuel cells: The role of phosphoric acid, ammonium trifluoromethanesulfonate, and polyvinylidene difluoride, $\mathrm{J}$. Power Sources. 272 (2014) 1072-1077. doi:10.1016/j.jpowsour.2014.09.035.

[11] Y.-J. Deng, G.K.H. Wiberg, A. Zana, M. Arenz, On the oxygen reduction reaction in phosphoric acid electrolyte: Evidence of significantly increased inhibition at steady state conditions, Electrochim. Acta. 204 (2016) 78-83. doi:10.1016/j.electacta.2016.04.065.

[12] D.F. Cheddie, N.D.H. Munroe, A two-phase model of an intermediate temperature PEM fuel cell, Int. J. Hydrogen Energy. 32 (2007) 832-841. doi:10.1016/j.ijhydene.2006.10.061.

[13] J.R. Vang, HTPEM fuel cell impedance - Mechanistic modelling and experimental characterisation, Aalborg University, Denmark, 2015.

http://vbn.aau.dk/da/publications/htpem-fuel-cell-impedance(87ac47da-fd09-4b3f-910a35bff751a509).html.

[14] T. Sousa, M. Mamlouk, K. Scott, A Non-isothermal Model of a Laboratory Intermediate Temperature Fuel Cell Using PBI Doped Phosphoric Acid Membranes, Fuel Cells. 10 (2010) 993-1012. doi:10.1002/fuce.200900178.

[15] T.D. Myles, S. Kim, R. Maric, W.E. Mustain, Application of a Coated Film Catalyst Layer Model to a High Temperature Polymer Electrolyte Membrane Fuel Cell with Low Catalyst Loading Produced by Reactive Spray Deposition Technology, Catalysts. 5 (2015) 16731691. doi:10.3390/catal5041673.

[16] S.J. Lee, S. Mukerjee, J. McBreen, Y.W. Rho, Y.T. Kho, T.H. Lee, Effects of Nafion impregnation on performances of PEMFC electrodes, Electrochim. Acta. 43 (1998) 36933701. doi:10.1016/S0013-4686(98)00127-3.

[17] W. Sun, B.A. Peppley, K. Karan, An improved two-dimensional agglomerate cathode model to study the influence of catalyst layer structural parameters, Electrochim. Acta. 50 (2005) 3359-3374. doi:10.1016/j.electacta.2004.12.009.

[18] K.E. Gubbins, R.D. Walker, The Solubility and Diffusivity of Oxygen in Electrolytic Solutions, J. Electrochem. Soc. 112 (1965) 469. doi:10.1149/1.2423575.

[19] K.E. Gubbins, R.D. Walker, Solubility and Diffusivity of Hydrocarbons and Oxygen in Fuel Cell Electrolytes, Gainesville, Florida, 1965.

[20] F. Gan, D.T. Chin, Determination of diffusivity and solubility of oxygen in phosphoric acid using a transit time on a rotating ring-disc electrode, J. Appl. Electrochem. 23 (1993) 452455. doi:10.1007/BF00707621.

[21] K. Klinedinst, J. a. S. Bett, J. Macdonald, P. Stonehart, Oxygen solubility and diffusivity in 
hot concentrated H3PO4, J. Electroanal. Chem. Interfacial Electrochem. 57 (1974) 281-289. doi:10.1016/S0022-0728(74)80053-7.

[22] C.P. Winlove, K.H. Parker, R.K.C. Oxenham, The measurement of oxygen diffusivity and concentration by chronoamperometry using microelectrodes, J. Electroanal. Chem. 170 (1984) 293-304. doi:10.1016/0022-0728(84)80051-0.

[23] X. Gang, H.A. Hjuler, C. Olsen, R.W. Berg, N.J. Bjerrum, Electrolyte Additives for Phosphoric Acid Fuel Cells, J. Electrochem. Soc. 140 (1993) 896-902. doi:10.1149/1.2056224.

[24] B.R. Scharifker, P. Zelenay, J.O. Bockris, The Kinetics of Oxygen Reduction in Molten Phosphoric Acid at High Temperatures, J. Electrochem. Soc. 134 (1987) 2714-2725. doi:10.1149/1.2100276.

[25] A. Essalik, O. Savagodo, F. Ajersch, Chemical and Electrochemical Parameters for Oxygen Reduction on Pt-H2WO4/Carbon Electrodes in 99\% H3PO4, J. Electrochem. Soc. 142 (1995) 1368-1376. doi:10.1149/1.2048584.

[26] Z. Liu, J.S. Wainright, M.H. Litt, R.F. Savinell, Study of the oxygen reduction reaction (ORR) at Pt interfaced with phosphoric acid doped polybenzimidazole at elevated temperature and low relative humidity, Electrochim. Acta. 51 (2006) 3914-3923. doi:10.1016/j.electacta.2005.11.019.

[27] M.A. Enayetullah, E.J.M. O'Sullivan, E.B. Yeager, Oxygen reduction on platinum in mixtures of phosphoric and trifluoromethane sulphonic acids, J. Appl. Electrochem. 18 (1988) 763-767. doi:10.1007/BF01016905.

[28] E. Heider, Z. Jusys, R.J. Behm, L. Jörissen, R. Zeis, Perfluoroalkyl-Phosphonic Acid Adsorption on Polycrystalline Platinum and Its Influence on the Oxygen Reduction Reaction, J. Phys. Chem. C. 119 (2015) 18859-18869. doi:10.1021/acs.jpcc.5b03858.

[29] F. Mack, S. Galbiati, V. Gogel, L. Jörissen, R. Zeis, Evaluation of electrolyte additives for high temperature PEM fuel cells, ChemElectroChem. (2016). doi:10.1002/celc.201500561.

[30] M. Tsushima, K. Tokuda, T. Ohsaka, Use of Hydrodynamic Chronocoulometry for Simultaneous Determination of Diffusion Coefficients and Concentrations of Dioxygen in Various Media, Anal. Chem. 66 (1994) 4551-4556. doi:10.1021/ac00096a024.

[31] J. McBreen, W.E. O'Grady, R. Richter, A Rotating Disk Electrode Apparatus for the Study of Fuel Cell Reactions at Elevated Temperatures and Pressures, J. Electrochem. Soc. (1984). doi:10.1149/1.2115782.

[32] S.J. Clouser, J.C. Huang, E. Yeager, Temperature dependence of the Tafel slope for oxygen reduction on platinum in concentrated phosphoric acid, J. Appl. Electrochem. 23 (1993) 597605. doi:10.1007/BF00721951.

[33] G.K.H. Wiberg, M.J. Fleige, M. Arenz, Design and test of a flexible electrochemical setup for measurements in aqueous electrolyte solutions at elevated temperature and pressure, Rev. Sci. Instrum. 85 (2014) 085105. doi:10.1063/1.4890826.

[34] M.J. Fleige, G.K.H. Wiberg, M. Arenz, Rotating disk electrode system for elevated pressures and temperatures, Rev. Sci. Instrum. 86 (2015) 064101. doi:10.1063/1.4922382.

[35] S.E. Morris, Hydrodynamic chronocoulometry, TrAC Trends Anal. Chem. 7 (1988) 227232. doi:10.1016/0165-9936(88)90011-8.

[36] D. Zhang, J. Wu, L. Mao, T. Okajima, F. Kitamura, T. Ohsaka, et al., Hydrodynamic 
chronocoulometric estimation of diffusion coefficients and saturated concentrations of dioxygen in KOH solutions, Indian J. Chem. 42A (2003) 801-806.

[37] J.F. Wu, Y. Che, T. Okajima, F. Matsumoto, K. Tokuda, T. Ohsaka, Hydrodynamic Chronocoulometric Determination of Diffusion Coefficients and Concentrations of Dioxygen in Media Containing Quinoline, Isoquinoline, and Methylquinolines, Anal. Chem. 71 (1999) 4056-4060. doi:10.1021/ac9901992.

[38] Y. Tani, T. Nohira, T. Enomoto, K. Matsumoto, R. Hagiwara, Solubility and diffusion coefficient of oxygen in 1-ethyl-1-methylpyrrolidinium fluorohydrogenate room temperature ionic liquid at 298-373K, Electrochim. Acta. 56 (2011) 3852-3856. doi:10.1016/j.electacta.2011.02.038.

[39] M. Haibara, S. Hashizume, H. Munakata, K. Kanamura, Solubility and Diffusion Coefficient of Oxygen in Protic Ionic Liquids with Different Fluoroalkyl Chain Lengths, Electrochim. Acta. 132 (2014) 208-213. doi:10.1016/j.electacta.2014.03.143.

[40] M. Inaba, H. Yamada, J. Tokunaga, A. Tasaka, Effect of Agglomeration of Pt/C Catalyst on Hydrogen Peroxide Formation, Electrochem. Solid-State Lett. 7 (2004) A474-A476. doi:10.1149/1.1814595.

[41] G.K.H. Wiberg, M. Arenz, Establishing the potential dependent equilibrium oxide coverage on platinum in alkaline solution and its influence on the oxygen reduction, J. Power Sources. 217 (2012) 262-267. doi:10.1016/j.jpowsour.2012.06.019.

[42] G.K.H. Wiberg, K.J.J. Mayrhofer, M. Arenz, Investigation of the Oxygen Reduction Activity on Silver - A Rotating Disc Electrode Study, Fuel Cells. 10 (2010) 575-581. doi:10.1002/fuce.200900136.

[43] J. Newman, Schmidt Number Correction for the Rotating Disk, J. Phys. Chem. 70 (1966) 1327-1328. doi:10.1021/j100876a509.

[44] P. Han, D.M. Bartels, Temperature Dependence of Oxygen Diffusion in H2O and D2O, J. Phys. Chem. 100 (1996) 5597-5602. doi:10.1021/jp952903y.

[45] T.R. Rettich, R. Battino, E. Wilhelm, Solubility of gases in liquids. 22. High-precision determination of Henry's law constants of oxygen in liquid water from $\mathrm{T}=274 \mathrm{~K}$ to $\mathrm{T}=328 \mathrm{~K}$, J. Chem. Thermodyn. 32 (2000) 1145-1156. doi:10.1006/jcht.1999.0581.

[46] M. Geng, Z. Duan, Prediction of oxygen solubility in pure water and brines up to high temperatures and pressures, Geochim. Cosmochim. Acta. 74 (2010) 5631-5640. doi:10.1016/j.gca.2010.06.034.

[47] A. Wexler, Vapor pressure formulation for water in range 0 to $100{ }^{\circ} \mathrm{C}$. A revision, J. Res. Natl. Bur. Stand. Sect. A Phys. Chem. 80A (1976) 775-785. doi:10.6028/jres.080A.071. 


\section{Figures}

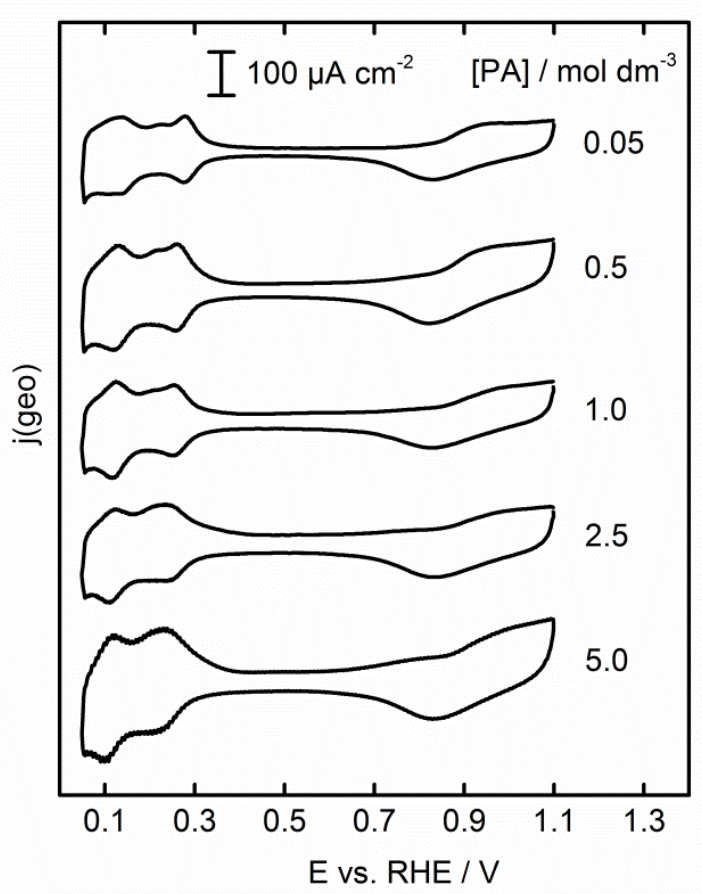

Fig. 1: Series of cyclovoltammograms recorded in unstirred Argon saturated phosphoric acid electrolyte in the concentration range $0.05-5.0 \mathrm{~mol} \mathrm{dm}^{-3} ; \mathrm{T}=25^{\circ} \mathrm{C}$, potential scan rate $=50 \mathrm{mV} \mathrm{s}^{-1}$.

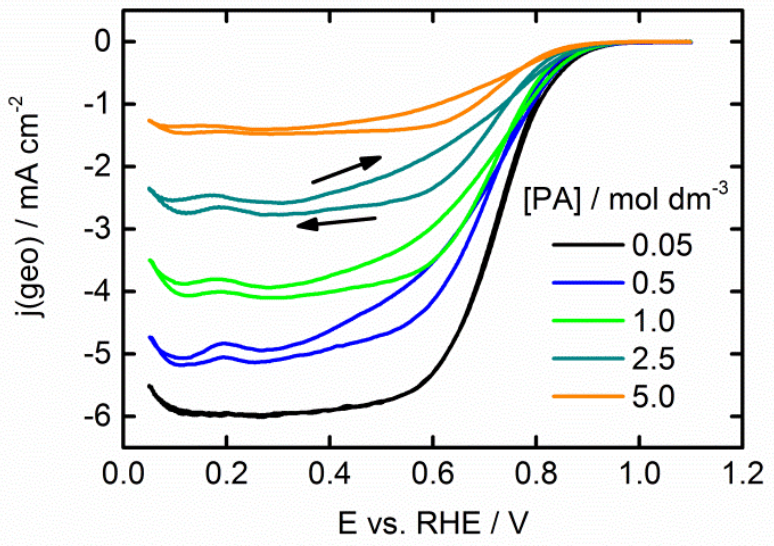

Fig. 2: Series of cyclovoltammograms recorded in $\mathrm{O}_{2}$-saturated phosphoric acid electrolyte in the concentration range $0.05-5.0 \mathrm{~mol} \mathrm{dm}^{-3}$ at atmospheric pressure. Cyclovoltammograms recorded in Argonsaturated electrolyte were subtracted. $\mathrm{T}=25^{\circ} \mathrm{C}$, potential scan rate $=100 \mathrm{mV} \mathrm{s}^{-1}$, rotation rate $=1600 \mathrm{rpm}$. 


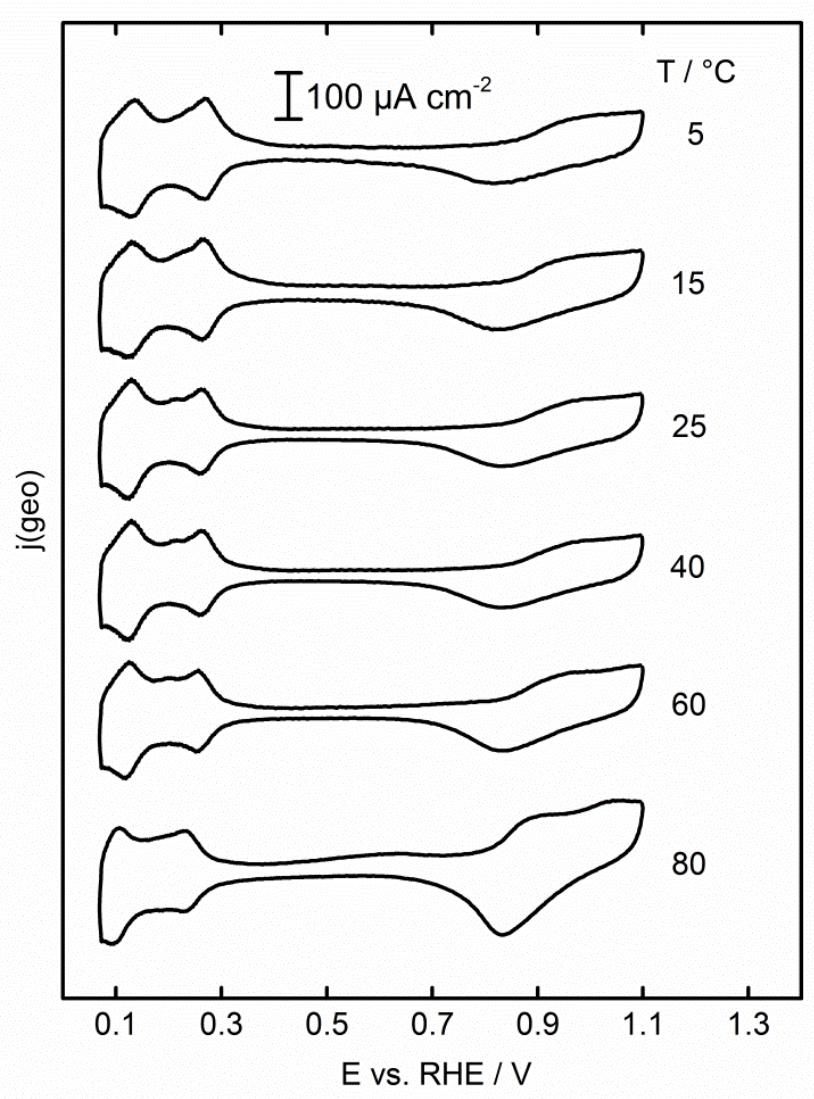

Fig. 3: Series of cyclovoltammograms recorded in unstirred Argon saturated phosphoric acid electrolyte in the temperature range $5-80{ }^{\circ} \mathrm{C}$, phosphoric acid concentration $=0.5 \mathrm{~mol} \mathrm{dm}^{-3}$, potential scan rate $=50 \mathrm{mV} \mathrm{s}^{-}$ 1 .
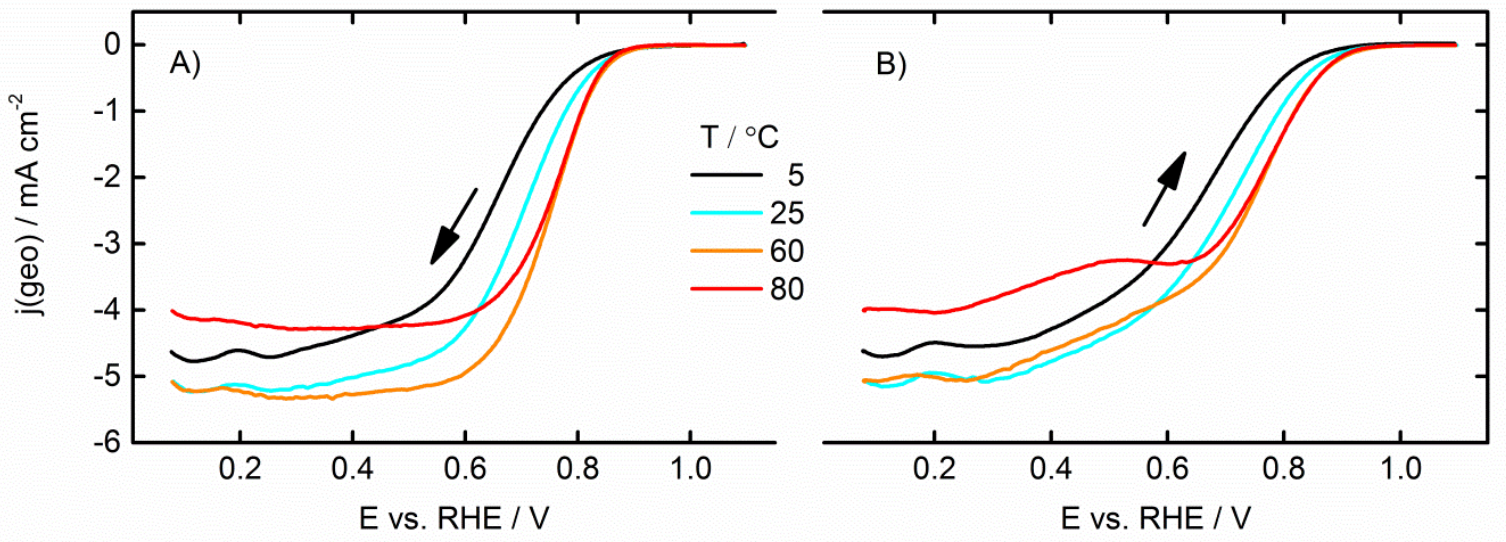

Fig. 4: Series of polarization curves recorded in $\mathrm{O}_{2}$-saturated phosphoric acid electrolyte at atmospheric pressure in the temperature range $5-80{ }^{\circ} \mathrm{C}$. A) negative going scan direction B) positive going scan direction. Corresponding polarization curves recorded in Argon-saturated electrolyte were subtracted; $\left[\mathrm{H}_{3} \mathrm{PO}_{4}\right]=0.5 \mathrm{~mol} \mathrm{dm}^{-3}$, potential scan rate $=100 \mathrm{mV} \mathrm{s}^{-1}$, rotation rate $=1600 \mathrm{rpm}$. 


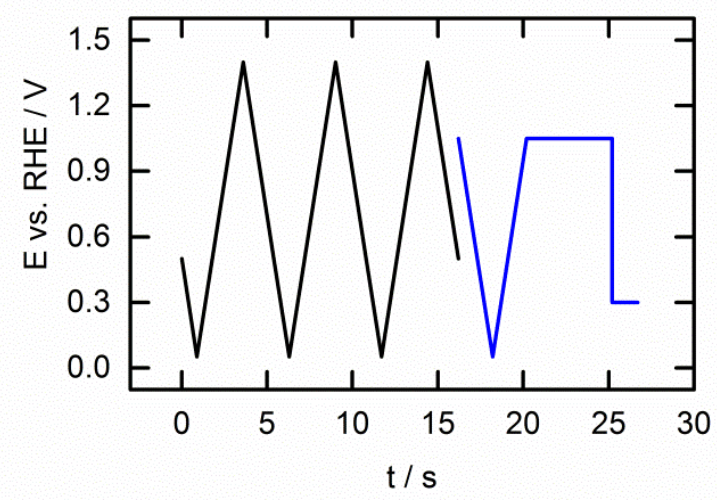

Fig. 5: Potential scan and potential step profile used in chronocoulometric measurements of concentration and diffusivity of $\mathrm{O}_{2}$ in phosphoric acid electrolyte.

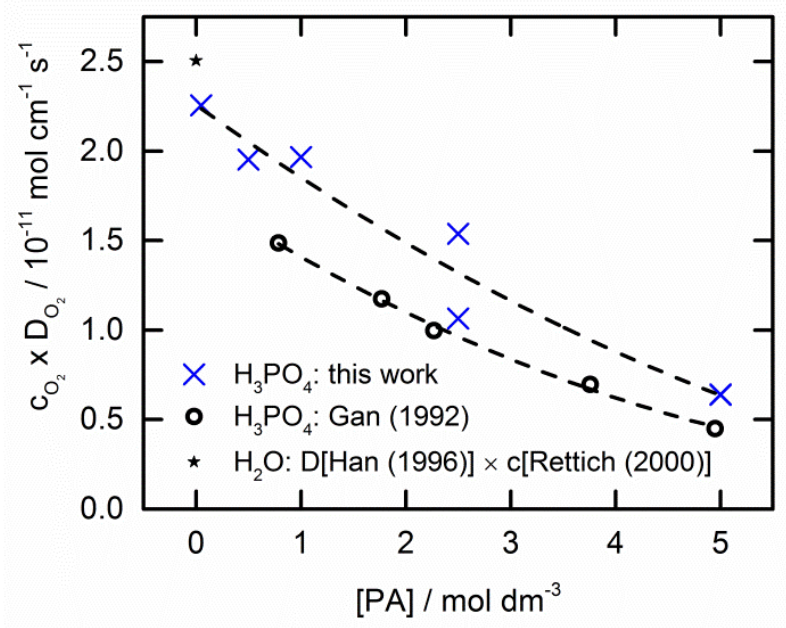

Fig. 6: Product of concentration and diffusivity of $\mathrm{O}_{2}$ in phosphoric acid in the concentration range of $0.05-$ $5.0 \mathrm{~mol} \mathrm{dm}^{-3}$ at $25^{\circ} \mathrm{C}$. 


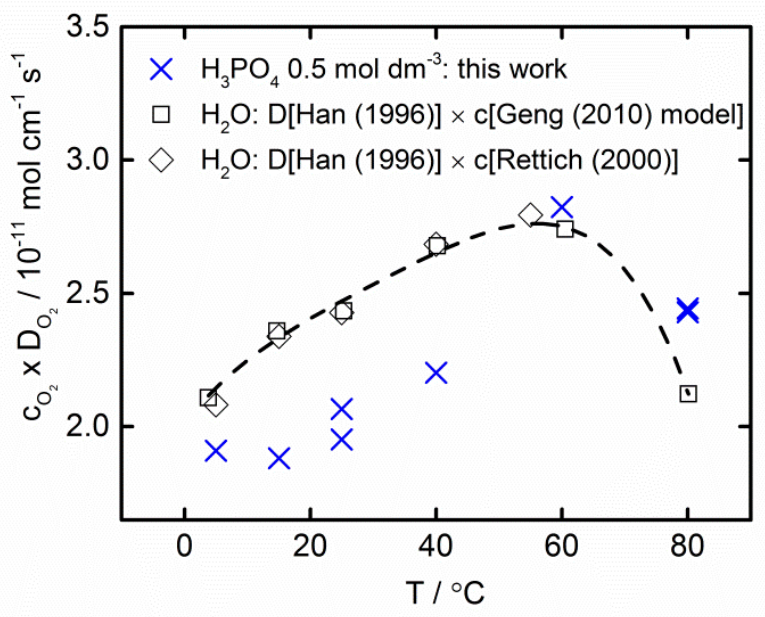

Fig. 7: Product $\mathrm{c}_{\mathrm{O}_{2}} \times \mathrm{D}_{\mathrm{O}_{2}}$ of concentration and diffusivity of $\mathrm{O}_{2}$ in $0.5 \mathrm{~mol} \mathrm{dm}{ }^{-3}$ phosphoric acid and in water calculated from literature values over the temperature range $3.8-80.1{ }^{\circ} \mathrm{C}$. The dashed line fitted to the combination of experimental values for diffusion in water and data from a solubility model serves as guide for the eye. 